\title{
Pantoea species causing early onset neonatal sepsis: a case report
}

\author{
Shreekant Tiwari ${ }^{1,3^{*}}$ and Siba Shankar Beriha ${ }^{2}$
}

\begin{abstract}
Introduction: Pantoea agglomerans is a plant pathogen which very rarely causes an opportunistic infection. Human beings are usually infected by thorn prick injuries or by contaminated parenteral fluids. Pantoea agglomerans has been reported as a cause of neonatal sepsis very rarely and to the best of our knowledge this is the first reported case from India.
\end{abstract}

Case presentation: A 4-day-old Asian baby boy from the rural area of Odisha, India, was admitted to our neonatal intensive care unit when he presented with fever, tachypnea and chest retraction. Pantoea species were isolated from his blood culture.

Conclusions: He was treated successfully with meropenem administered intravenously and other supportive measures. Early detection and proper management may cause a favorable outcome.

\section{Introduction}

Pantoea agglomerans, formerly known as Enterobacter agglomerans, is a member of family Enterobacteriaceae. It is primarily an environmental and agricultural organism that inhabits plants, soil and water. It is an opportunistic pathogen and very rarely causes disease in healthy individuals [1]. The most common infections caused by Pantoea agglomerans are septic arthritis or synovitis, cholelithiasis, occupational respiratory infections and skin allergy, peritonitis and blood stream infection in an elderly person [2]. It is an unusual pathogen in the etiology of neonatal sepsis. Here we report a blood stream infection caused by Pantoea species (spp.) in a term baby which was delivered vaginally and this is the first documented case from India.

\section{Case presentation}

A 4-day-old Asian baby boy was delivered vaginally at term in our hospital; he was referred to our neonatal intensive care unit (NICU) 48 hours after delivery when he presented with fever, tachypnea and chest retraction. His birth weight was $2.9 \mathrm{~kg}$ and he cried immediately after delivery. His mother was 19-years old and she came

\footnotetext{
* Correspondence: drshreekant@rediffmail.com

'Department of Microbiology, Hi-Tech Medical College \& Hospital, Bhubaneswar, Odisha, India

${ }^{3}$ Kathagola Sahi, Mangalabag, Cuttack, Odisha PIN-753001, India

Full list of author information is available at the end of the article
}

from a rural area. Her antenatal history revealed that she had undergone regular checkups at our hospital; she had no bad obstetric history during the whole pregnancy period. On examination it was found that her human immunodeficiency virus (HIV), hepatitis B virus (HBV) and hepatitis $\mathrm{C}$ virus (HCV) status was negative by enzyme-linked immunosorbent assay (ELISA) method. No vaginal lesions were identified during pregnancy and there was no history of birth trauma. She gave a history of premature rupture of membrane (PROM) approximately 8 to 10 hours before delivery. She noted a foul smelling discharge after rupture of membrane.

The baby boy had respiratory distress with some pneumonic changes seen on chest X-ray. A blood sample was collected with complete aseptic precaution into aerobic and anaerobic blood culture bottle (BacT/ALERT ${ }^{\circ}$ 3D; bioMérieux, Marcy-l'Etoile, France). He was then empirically treated with a combination of amikacin and vancomycin. Aliquots of broth were subcultured on 5\% sheep blood agar and MacConkey agar. On blood agar plate colonies were pin-point and had a smooth surface, whereas on MacConkey agar there was a lactosefermenting colony with similar morphology. A routine biochemical test showed that the colony belonged to the family Enterobacteriaceae and further identification was performed by Vitek 2 using GN25 card (bioMérieux, Marcy-l'Etoile, France); it was identified as Pantoea spp. 
with $97 \%$ probability. Isolates were sensitive to imipenem, meropenem, amikacin, cefoperazone-sulbactam, ceftriaxone and netilmicin, and resistant to gentamicin, cefotaxime and ceftazidime-clavulanic acid. The anaerobic culture bottle showed no growth after 7 days of incubation. A high vaginal swab of the mother was also sent for culture and sensitivity and it also showed growth of Pantoea spp. Other laboratory parameters were: hemoglobin (Hb) $10 \mathrm{gm} \%$, red blood cell (RBC) $4.49 / \mathrm{cmm}^{3}$, total leukocyte count (TLC) 41,000, neutrophil 80\%, lymphocyte $16 \%$, monocyte $4 \%$, C-reactive protein (CRP) $22.5 \mathrm{mg} / \mathrm{L}$, urea $73.5 \mathrm{mg} / \mathrm{dl}$, serum creatinine $0.45 \mathrm{mg} / \mathrm{dl}$, sodium $\left(\mathrm{Na}^{+}\right)$ $141 \mathrm{mmol} / \mathrm{L}$ and potassium $\left(\mathrm{K}^{+}\right) 4.8 \mathrm{mmol} / \mathrm{L}$. After collection of the blood sample the baby boy was treated empirically with vancomycin and amikacin. His therapy was changed to meropenem and he was successfully treated with 1 gram twice daily for 14 days after getting the sensitivity report.

\section{Discussion}

Pantoea spp. is an opportunistic pathogen and rarely causes disease in healthy individuals. Infections caused by Pantoea spp. have been reported in samples obtained from cotton swabs, intra-arterial devices as well as plants and plant material [3]. Cotton swabs are continuously used by nurses and physicians in hospital and can be contaminated in many ways. Pantoea spp. is often associated with outbreaks due to contaminated intravenous solutions and stored blood products. Pantoea spp. when involved in a systemic infection has a predilection for the lungs.

The common pathogens causing early onset neonatal sepsis are Klebsiella pneumoniae, Serratia marcescens, group B streptococcus, Escherichia coli, coagulase-negative staphylococci and Pseudomonas spp. [4, 5]. Pantoea spp. is a very rare pathogen causing early onset neonatal sepsis. To the best of our knowledge this is the first case report of Pantoea spp. causing early onset neonatal sepsis from India in an otherwise term baby exposed to PROM. All the previous case reports had been associated with significant prematurity and comorbidity but a similar case report in a near-term baby was reported by Lalas and Erichsen [6] (see Table 1).

Infections caused by Pantoea agglomerans are usually associated with an identifiable exogenous source [7]. These organisms grow well at $4{ }^{\circ} \mathrm{C}$ and most commonly cause septic arthritis or synovitis following a penetrating injury by vegetation. Organic materials like plant thorn may penetrate the skin and remain embedded in the tissues and set up a chronic inflammatory process $[8,9]$.

Although Escherichia coli is a common cause of vertically transmitted infection in the new born, Pantoea

Table 1 Summary of cases of Pantoea agglomerans causing neonatal sepsis

\begin{tabular}{|c|c|c|c|c|c|c|c|c|c|}
\hline Study group and Reference number & GA (weeks) & BW (gram) & Gender & $A D$ (days) & Comorbidity & Symptoms & IC & $\mathrm{CF}$ & Outcome \\
\hline This study & FT & 2900 & M & 4 & PROM, RDS & $\mathrm{RD}$ & No & No & Survived \\
\hline Lalas and Erichsen [6] & 35 & 1990 & $\mathrm{~F}$ & 2 & PROM & $\mathrm{RD}$ & No & No & Good \\
\hline Bergman et al. [10] & 29 & 1795 & UK & 5 & RDS, PROM & RD, shock, DIC & Yes & No & Death \\
\hline Bergman et al. [10] & 28 & 60 & UK & 20 & IUGR, RDS & RD, shock, DIC & Yes & No & Death \\
\hline Bergman et al. [10] & 40 & 3810 & UK & 12 & CHD, PDA & $\mathrm{RD}$, shock, DIC & Yes & No & Death \\
\hline Habsah et al. [11] & 26 & 950 & UK & 11 & RDS & RD, shock, DIC & Yes & Yes & Death \\
\hline Habsah et al. [11] & 40 & 3300 & UK & 4 & Asphyxia & RD, shock, DIC & Yes & Yes & Death \\
\hline Habsah et al. [11] & 32 & 1500 & UK & 3 & RDS & RD, shock, DIC & Yes & Yes & Survived \\
\hline Habsah et al. [11] & 40 & 3200 & UK & 5 & VACTERL & RD, shock, DIC & Yes & Yes & Death \\
\hline Habsah et al. [11] & 36 & 1670 & UK & 5 & IUGR & RD, shock, DIC & Yes & Yes & Death \\
\hline Habsah et al. [11] & 36 & 2000 & UK & 4 & Asphyxia & RD, shock, DIC & Yes & Yes & Death \\
\hline Habsah et al. [11] & 26 & 1200 & UK & 5 & RDS & RD, shock, DIC & Yes & Yes & Death \\
\hline Cruz et al. [9] & $\mathrm{FT}$ & UK & $\mathrm{F}$ & 24 & Cardiomyopathy & UK & Yes & No & Death \\
\hline Cruz et al. [9] & FT & UK & M & 16 & Coarctation & UK & Yes & No & Survived \\
\hline Aly et al. [12] & 30 & 1500 & M & 13 & RDS & RD, Shock & Yes & No & Survived \\
\hline Aly et al. [12] & 29 & 1030 & M & 12 & RDS & RD, Shock & Yes & No & Survived \\
\hline Aly et al. [12] & 28 & 815 & $\mathrm{~F}$ & 17 & Pre-NEC & RD, Shock & Yes & No & Survived \\
\hline Aly et al. [12] & 26 & 855 & M & 8 & RDS, PDA & RD, Shock & Yes & No & Survived \\
\hline Aly et al. [12] & 27 & 1020 & $\mathrm{~F}$ & 11 & RDS, PDA & RD, Shock & Yes & No & Survived \\
\hline
\end{tabular}

$A D$ age at diagnosis, $B W$ birth weight, $C F$ contaminated fluids, $C H D$ congestive heart disease, DIC disseminated intravascular coagulation, $F$ female, $F T$ full term, $G A$ gestational age, IC indwelling catheters, IUGR intrauterine growth retardation, $M$ male, NEC necrotizing enterocolitis, PDA patent ductus arteriosus, $P R O M$ prolonged rupture of membrane, $R D$ respiratory distress, $R D S$ respiratory distress syndrome, UK unknown, VACTERL vertebral anomalies, anal atresia, cardiovascular anomalies, tracheoesophageal fistula, esophageal atresia, renal anomalies, limb anomalies 
agglomerans infection could also be the result of exposure to colonizing bacteria in the birth canal following PROM. A similar case was reported by Lalas and Erichsen in 2010 [6]. Although it is very difficult to draw any conclusion from a single case, it should be kept in mind that Pantoea spp. could be a rare cause of vertically transmitted infection in a term baby.

\section{Conclusions}

Pantoea spp. is a rare pathogen in the etiology of early onset neonatal sepsis. In the majority of previous cases, the outcome was very poor because of association with prematurity and comorbidity. In our case the outcome was excellent because it was a term baby, the antibiotic meropenem was administered intravenously and other supportive measures like oxygen were given in time. Early detection and proper antibiotic therapy may cause a favorable outcome despite significant clinical deterioration.

\section{Consent}

Written informed consent was obtained from the patient's legal guardian(s) for publication of this case report and any accompanying images. A copy of the written consent is available for review by the Editor-in-Chief of this journal.

\section{Abbreviations}

NICU: Neonatal intensive care unit; PROM: Premature rupture of membrane; Spp.: Species.

\section{Competing interests}

The authors declare that they have no competing interests.

\section{Authors' contributions}

ST contributed in the preparation of manuscript, data analysis and interpretation of the data. SSB contributed in data analysis and drafting of manuscript. Both authors read and approved the final manuscript.

\section{Author details}

'Department of Microbiology, Hi-Tech Medical College \& Hospital, Bhubaneswar, Odisha, India. ${ }^{2}$ SVBP Post Graduate Institute of Paediatrics, Shishu Bhawan, Cuttack, Odisha, India. ${ }^{3}$ Kathagola Sahi, Mangalabag, Cuttack, Odisha PIN-753001, India.

Received: 9 December 2014 Accepted: 10 August 2015

Published online: 04 September 2015

\section{References}

1. Liberto MC, Matera G, Puccio R, Lo Russo T, Colosimo E, Focà E. Six cases of sepsis caused by Pantoea agglomerans in a teaching hospital. New Microbiol. 2009:32:119-23.

2. Van Rostenberghe H, Noraida R, Wan Pauzi WI, Habsah H, Zeehaida M, Rosliza AR, et al. The clinical picture of neonatal infection with Pantoea species. Jpn J Infect Dis. 2006;59:120-1.

3. Sander Jr WE, Sanders CC. Enterobacter spp. pathogens poised to flourish at the turn of the century. Clin Microbiol Rev. 1997;10:220-41.

4. Ananthakrishnan S, Gunasekaran D. Etiology and risk factors for early onset neonatal sepsis. Indian J Med Microbiol. 2009:27:279.

5. Mutlu M, Aslan Y, Saygin B, Yilmaz G, Bayramo Lu G, Köksal I. Neonatal sepsis caused by Gram-negative bacteria in a neonatal intensive care unit: a six year analysis. HK J Paediatr (New series). 2011;16:253-7.
6. Lalas KM, Erichsen D. Sporadic Pantoea agglomerans bacteremia in a near term female: case report and review of literature. Jpn J Infect Dis. 2010;63:290-1.

7. Matsaniotis NS, Syriopoulou VP, Theodoridou MC, Tzanetou KG, Mostrou GI. Enterobacter sepsis in infants and children due to contaminated intravenous fluids. Infect Control. 1984;5:471-7.

8. Jain S, Bohra I, Mahajan R, Jain S, Chugh TD. Pantoea agglomerans infection behaving like a tumor after plant thorn injury: an unusual presentation. Indian J Pathol Microbiol. 2012;55:386-8.

9. Cruz AT, Cazacu AC, Allen CH. Pantoea agglomerans, a plant pathogen causing human disease. J Clin Microbiol. 2007;45:1989-92.

10. Bergman KA, Arends JP and and Scholvinck EH. Pantoea agglomerans septicemia in three newborn infants. Pediatr. Infect. Dis. J 2007;26:453-4.

11. Habsah H, Zeehaida M, Van Rostenberghe H, Noraida R, Wan Pauzi WI, Fatimah I, Rosliza AR, Nik Sharimah NY, Maimunah H. An outbreak of Pantoea spp. in a neonatal intensive care unit secondary to contaminated parenteral nutrition. J. Hosp. Infect. 2005;61:213-8.

12. Aly NY, Salmeen HN, Lila RA, Nagaraja PA. Pantoea agglomerans bloodstream infectionin preterm neonatees. Med. Princ. Pract. 2008;17(6):500-3.

\section{Submit your next manuscript to BioMed Central and take full advantage of:}

- Convenient online submission

- Thorough peer review

- No space constraints or color figure charges

- Immediate publication on acceptance

- Inclusion in PubMed, CAS, Scopus and Google Scholar

- Research which is freely available for redistribution 